\title{
Serving and love - Values in ethical nursing leadership
}

\author{
Leena Honkavuo* \\ Department of Caring Science, Division for Social Sciences, University of Åbo Akademi, Finland
}

Received: November 25, 2018

DOI: $10.5430 /$ jha.v8n2p30
Accepted: February 26, 2019 Online Published: March 18, 2019

URL: https://doi.org/10.5430/jha.v8n2p30

\begin{abstract}
Background: The significance of ethical and serving nursing leadership is the greatest contributing factors to attain good and quality assured care for patients. Prioritizing an ethical attitude and value base within the different levels of healthcare organizations opens up for well-being among patients, nurses, and nurse leaders. Polarization and many restructurings have changed the value base of healthcare organizations and the nursing culture so that serving and ethical values have been deprioritised rather than reinforced. Objective: To deepen the understanding of serving and ethical nursing leadership and to examine how nurse leaders through their ethos can pave the way toward the evident - the good, the truthful and the beautiful serving in the context of nursing administrations.

Methodology: Qualitative, descriptive and hermeneutic approach with inductive elements. The material consists of deep interviews with six nurse leaders. The hermeneutic reading act and interpretation of the interview texts are inspired by HansGeorg Gadamer's philosophical thought.

Results: Ethical leadership that serves the guest of honour of the healthcare organization, the patient, and the caring culture are made visible in the context of nursing administration through "The good, the truthful and the beautiful" timeless movement directed toward health, healing and the meaning of life. Ethos gives to nursing leadership a value base and fundamental attitude, and is linked to the responsibility of nursing administrations, dignity and holiness.

Implications for nursing management: Ethical and serving nurse leaders are attractive and legitimate role models for today's nursing administrations. Nurse leaders' direct influence, ethos and serving are factors that are closely connected with the ethical climate of the healthcare organization.
\end{abstract}

Key Words: Ethics, Ethos, Hermeneutics, Nursing administration, Nursing leadership, Serving

\section{INTRODUCTION}

The discussion of ethical values in healthcare organizations has been an area of great interest in recent decades and it looks like the debate will continue. Scholars from different disciplines and professionals in healthcare organizations alike have contributed to it. ${ }^{[1-4]}$ Nurse leaders experience disharmony and tensions in healthcare organizations when forced to choose between, on the one hand, the ethical, the good, the truthful and the beautiful caring and, on the other, the multifaceted demands from process in nursing adminis- trations. The values of healthcare organizations are seen as the point of departure for work in nursing administrations, but in this field of tension soft and hard values are pitted against each other and there is a concern for individuals. This concern includes a sense of being and losing one's ethical identity as the value base of healthcare organizations are viewed as unstable because of inhuman challenges and changes. ${ }^{[2,5,6]}$

Nursing leadership as a dichotomous concept carries the

*Correspondence: Leena Honkavuo, PhD, RN, CM; Email: honkavuo@ hotmail.com; Address: Universitetet Åbo Akademi, Samhälls- och socialvetenskapliga fakulteten, Enheten för vårdvetenskap, PB 311, 65101 Vasa, Finland. 
components nursing and leadership. Nursing and caring refer to the alleviation of suffering, the healing dynamics of health and the recognition of the human being. In this way, caring is seen as a healing process, a profound motive and mission in a leadership toward unity and holiness. Nursing administrations have on a micro level developed from nursing and refer to the core, task and driving force of caring. The concepts ministration, minister and ministro derive from Latin and refer to serving. ${ }^{[7]}$ The task and missio of nursing administrations are serving and developing and enabling knowledge that contributes to the creation of evidence-based caring. Their task should point towards the value base and plans of healthcare organizations. Nursing administrations are also seen as a bridge to management science and are created and change through the emergence of social influences and their new shapes. ${ }^{[8]}$

Antiquity has paved the way for ethical thinking. Plato's philosophy in particular opened for the classic, logical thinking that unites "The truthful, the good and the beautiful". ${ }^{9]}$ The place of truth is found in a value judgement which in the present study is connected with the ethos of caring science and nursing leadership and with caring ethics that is based on moral, love and mercy. ${ }^{[10-12]}$ The theoretical perspective of this study is based on Eriksson's humanistic and autonomous caring science tradition and includes the ontological evidence of the truthful, the beautiful and the good which refers to what is meaning-bearing and lasting in caring. ${ }^{[13]}$ This basis for this evidence originates in the innermost and original core of caring, service. Based on the caring science perspective, the evidence in nursing leadership and nursing administration reflects a hierarchy of values, an ethos. ${ }^{[5,14,15]}$ This means that the highest possible is truth and that the caring science ontological evidence is the criterium of truth. What is ethical in nursing leadership, rooted in serving, ethos and love, is evident knowledge and therefore possible to attain partly through caring science studies and partly through the ontology of caring science.

According to caring science thought, ethos and ethics belong together and become one through knowledge-moulding cultivation. Ethos sets the course in the evidence. ${ }^{[11,14]}$ Ethos is realized in the nurse leaders' innermost being and is recognized trough a real and evident way of action in a living caring culture and nursing administration communion. Ethos is expressed in the ethics of caring, inner harmony and willingness in what is and what in serving, nursing leadership and nursing administration opens up for truth. ${ }^{[5]}$ Ethics affirms the human being's dignity and is given to the individual through his or her existence. It cannot be taken from or restricted. ${ }^{[16,17]}$ In caring ethics emerges an aestheticizing feature of feeling - a moral and aesthetic pleasure in respect for the unique human being's dignity. The ethics of caring is the principal archetype for ethical good that manifests in nursing leadership through genuine desire, nursing administrational responsibility, dignity and holiness. ${ }^{[5,10,17,18]}$

The primary substance of interhuman love realizes the good, the truthful and the beautiful in the innermost core of caring as an ethical act. The ethical content of the highest commandment in the golden rule from the 17 th century and the Bible: You shall love your neighbour as yourself. The golden rule describes the true meaning of nursing leadership and expresses the normative duty of what the nurse leader should do and virtues of how they can realize their moral and ethical serving in nursing administrations. ${ }^{[18]}$ The highest commandment in itself carries the natural and unbound harmonious spirit of humanity. The real, truthful, beautiful and unconditional love has no boundaries or asks who the neighbour or fellow being is but motivates for and calls to the acts of love of the mind, hands and heart that is at the core of compassion.

The aim of this qualitative study is to deepen the understanding of ethical values in nursing leadership and describe how nurse leaders through their ethos can pave the way toward the evident - the good, the truthful and the beautiful in the context of nursing administrations. The study seeks to answer the following thematic research questions: What is serving and love in nursing leadership? How can nurse leaders' ethical value base, ethos, support nurses in a context of nursing administrations? How can nurse leaders' ethos be shown in nursing administrations through the classic and logical thinking: "The truthful, the good and the beautiful"?

\section{Previous research}

Previous studies describe what is ethical and serving in nursing leadership and that which is constructed by parts and hermeneutic wholes. Each part contributes to shaping ethics and manifests through the social face of healthcare organizations.

According to Detert et al. ${ }^{[19]}$ and Hannah et al., ${ }^{[20]}$ the ideal of the ethical nurse leader is tied to the human being's dignity and morals. Honesty, reliability, justice and altruistic actions for the good of one's fellow being are central principles both in professional posts and the private individual in society. Ethical nurse leaders are interested in ethical values: they are role models and a face for healthcare organizations. They discuss ethical issues, clarify the ethical values and norms of the healthcare organizations and follow up on moral issues and normative actions. ${ }^{[21,22]}$

Cara, Nyberg and Brousseau ${ }^{[23]}$ and Bjarnason and Lasala ${ }^{[24]}$ explain that changes and restructurings where decisions must be made quickly and on a broad front change the culture 
and spirit of healthcare organizations. The goal of saving money and increasing effectivity results in ethical sufferings. Although it is possible to prove the noticeable effects of an ethical nursing leadership, it receives only scant attention. ${ }^{\text {[25] }}$ Van Dierendonck \& Nujiten ${ }^{[26]}$ explain that healthcare organizations need more ethical nurse leaders who are interested in the human being and human-centred management instead of bureaucratic administrations. Nurse leaders should be inspired by an ethical and serving nursing leadership. Honkavuo $^{[5]}$ opens up for the ethos and ethics of serving in nursing leadership that can be especially important for today's healthcare organizations when serving their guest of honour - the patient and the patient's cause - and ethical thinking is diminished by the powers of market economy, productivity and business thinking. Patterson ${ }^{[27]}$ introduces a theoretical model of serving nursing leadership. This model has potential for future nursing leadership because serving is an ideal and an important key element for nursing leadership. Rushton et al. ${ }^{[28]}$ proposes a paradigm with ethics as a standard for nursing as an antidote to current ways of managing care in healthcare organizations. According to Mannix et al. ${ }^{[29]}$ it is time to open for aesthetic nurse leadership which is based on good and moral standing and serving in clinical nursing practice.

Nursing leadership is a process with a clear goal. During this process serving nurse leaders strive to influence those they lead to be able to steer their work in a more ethical direction. ${ }^{[30,31]}$ Nurse leaders' desire to act as good nurse leaders is tied to leadership style. There is a correlation between nurse leaders' presenting good and ethical nursing leadership and nurses' overall feeling of content or discontent as regards their workplace. ${ }^{[32]}$ Ethical nursing leadership was implemented in praxis after a specific program emphasizing the caring tradition and serving was developed. The results showed a change in the nurse leaders' thinking and leadership style toward the ethical, which resulted in positive effects for the nurses. ${ }^{[33,34]}$ Legitimate, reliable and strong personalities are a pre-condition for ethical nursing leadership. Nurse leaders can invite nurses to solidarity and trust, and thereby nurses can better identify as a part of the healthcare organization. This invitation also includes support for an ethical caring culture and equal communication. ${ }^{[35]}$ Responsibility in nursing leadership is a corner stone. According to De Hoogh \& Den Hartog, ${ }^{[30]}$ responsibility is connected with morals, justice and delegation of power. To attain the beneficial effects of the ethical in nursing leadership several features in nurse leaders can be distinguished: moral behaviour, a sense of inner duty, the ability to assess oneself, serving the nurses and awareness of the effects of one's actions.
The majority of earlier studies that focus on nursing leadership call attention to pragmatic issues: nurse leaders' attitudes and treatment. These emphasize ethical nursing leadership and leadership in nursing administrations while less attention is given to the art of nursing leadership. Nurse leaders' central position, conscious value base and ethos are highlighted especially when healthcare organizations experience pressures to change. Healthcare organizations have a different responsibility from other types of companies or industries: it is the responsibility towards society. The task of healthcare organizations is to represent society. This means that they have an ethical and moral responsibility to enable the development of nursing administrations and nursing leadership, which spurs practical acts of serving and legitimation. The future nurse leaders are called upon to face new challenges every day. For future research it would be interesting to publish papers that discuss good ethical or less good ethical behaviour as well as the challenges nurse leaders have to face daily. It is important that the debate on nurse leadership and management ethics continues and that as many contributors as possible are made to the construction of successful and valuable healthcare organizations for the whole society.

\section{Methodology}

The methodology of this study is rooted in caring science and Hans-Georg Gadamer's philosophical hermeneutics. Gadamer suggests that when the human being seeks new knowledge and new understanding the new understanding includes a truthful and heuristic value. ${ }^{[36]}$ The methodology is descriptive and explorative and comprises inductive elements based on the empiricism of the study from six nurse leaders. In the present study hermeneutics opens the way to the essence of serving and what is ethical in the depth of nursing leadership through the corresponding principles of the dialogue that aims at enabling a more profound level of experience in the human being.

The hermeneutic reading act has controlled the interpretation of the text and its content. The Gadamerian hermeneutic interpretation was circular in nature and was based on the research questions and aim of this study. A first reading was carried out for the purpose of having an initial understanding of the whole and the separate texts. The following reading sought new understanding to uncover a greater and deeper whole. The texts were read a number of times to further increase the understanding of the object of study (see Figure 1). A lingering reading of parts and whole sought answers through interpretation in the following semi-structured research questions:

- What is ethical nursing leadership?

- How does the ethical movement manifest in the nurse 
leader's serving in nursing administrations?

- How can nurse leaders protect serving and the ethical value base in healthcare organizations?

In the closing, meaning-bearing cardinal themes resulted from the interpretation. In accordance with Gadamer, ${ }^{[36]}$ it was possible to attain a horizon of understanding for a serving and ethical nursing leadership and describe how nurse leaders can safeguard the good, the truthful, and the beautiful in the meaning context of nursing administrations.

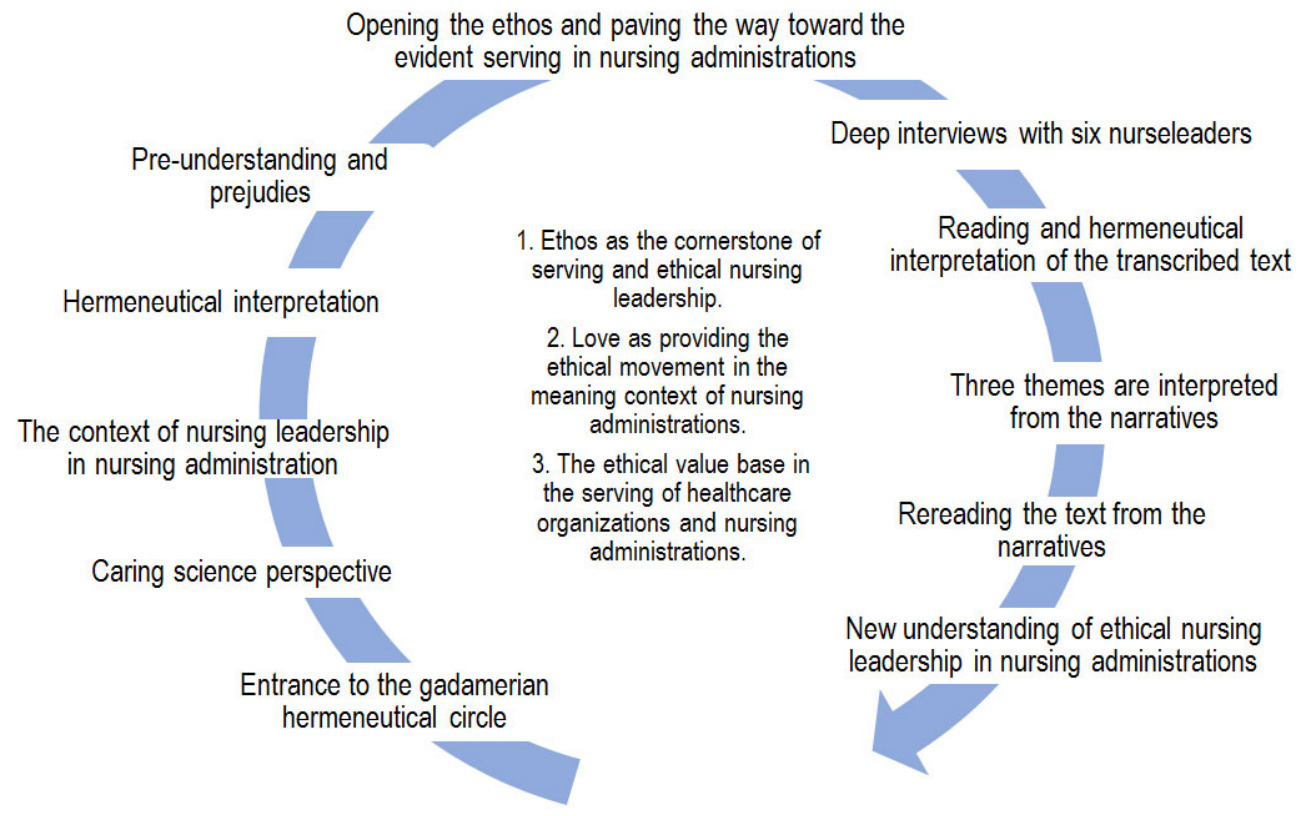

Figure 1. The movement in the Gadamerian hermeneutic circle is infinite and has no beginning or end. It describes the whole-part interpretations of understanding in the context of nursing leadership in nursing administration. Three cardinal themes have given form through hermeneutical interpretations from six nurse leaders' narratives.

\subsection{Data collection and participants}

The material of this study consists of texts from conversational deep interviews with six Norwegian nurse leaders from a strategically chosen university hospital. The information about the study was conveyed to the participants through the leading nurse of the hospital. The participants were women between the ages of 38 and 61 . They were all trained nurses and had knowledge about caring science. Their work was combined with nursing administrational tasks and clinical nursing, and they all worked full-time. Work experience as a nurse leader varied between 2 and 23 years. The information about the conversational deep interview was conveyed both orally and in writing beforehand. All of the participants signed a form of consent with information about voluntariness, confidentiality and the right to discontinue their participation at any time. The conversational deep interviews lasted from 45 to 60 minutes with possibility for flexibility and were conducted at the premises of the hospital. A pilot study was carried out before the deep interviews to examine whether the questions prepared and developed by the researcher were sufficient and whether the number of participants was satisfactory to achieve saturation.
The deep interviews began by obtaining demographic data: the participants' age, education and work experience. The semi-structured questions guided the open dialogue of the conversations and the participants showed the way forward with the answers. The researcher initially articulated her preunderstanding, interest and motive for the choice of research area, which had the function of a door opener for the deep interviews. According to Kvale \& Brinkmann, ${ }^{[37]}$ an open listening, respect and understanding are required from the researcher. In qualitative, conversational and hermeneutic interviews the researcher is invited and may enter the world of the participant. In a lingering wonder it is possible for the researcher to describe the conversation by listening to what is told and what is untold. The interview situation felt sincere and the participants could express themselves with openness and free reasoning. The interviews were taped for transcription and the hermeneutic interpretation. The collected material consists of 59 pages of text.

\subsection{Ethical considerations}

General laws of research ethics, instructions, principles, rules and norms are taken into consideration according to the World Medical Association Declaration of Helsinki, ${ }^{[38]}$ 
the Northern Nurses' Federation, ${ }^{[39]}$ the International Council of Nurses ${ }^{[40]}$ and the Norwegian social science data services. ${ }^{[41]}$ In accordance with these ethical guidelines carefulness, meticulousness and honesty were observed during all phases of the study. An ethical attitude, openness and responsibility, protection of and respect for the material and the dignity of the human being have been considered. Ethical consideration is directed towards the participants, their narratives and anonymity.

\section{RESUlts}

The results are based on the aim of this study, semi-structured questions, narratives from six nurse leaders and hermeneutic interpretation. The results relate to the caring science theoretical perspective of the study and to previous research. Three themes were interpreted from the narratives:

(1) Ethos as the cornerstone of serving and ethical nursing leadership;

(2) Love as providing the ethical movement in the meaning context of nursing administrations;

(3) The ethical value base in the serving of healthcare organizations and nursing administrations.

\subsection{Ethos as the cornerstone of serving and ethical nurs- ing leadership}

Serving is the point of departure for the ethos and nursing administration of nursing leadership. Nurse leaders serve and are active in the service of the nursing administration. The good, truthful and beautiful - the idea of serving and ethical leadership is expressed as authoritative, accepting, developing, true and humble. Ethos is the cornerstone upon which ethical nursing leadership and nursing administration rest. It is dynamic and under continuous movement and growth.

The ethical in nursing leadership is a form of indicator of good results. After all, we are here to achieve good results when it comes to serving patients and their illnesses. As a nurse leader I lead the way for the nurses as a role model. Each individual is valuable... they should be provided with the support they need.

The desire and willingness to serve involves ethical acts of love and compassion with the intention of promoting health and alleviating suffering as a defence for the dignity of the human being. The emotionally charged cardinal virtues are conveyed in nursing leadership through holy willingness, courage and knowledge through faith, hope and all-inclusive unselfish love in the pure actions of charity.

One has to want to and enjoy leading... be able

to handle it and actually believe in it... Ethical nursing leadership and value thinking is something that I want to develop further in my work. Then my nursing leadership becomes a strength for me and the nurses.

The principle of responsibility represents the core in what is ethical. Through their ethos and position, nurse leaders influence people in healthcare organizations. Nurse leaders' responsibility in nursing administrations and the mandate to introduce ethical values to healthcare organizations is integrated into the work task. Nursing administrational responsibility in nursing leadership contains the attributes of serving. It is a natural part of nurse leaders' ontology and a condition for love.

To think in an ethical way... This is when nurse leaders implement the core ethical values in their work... that which controls our lives here in the unit. The ethical means responsibility. I have an ethical responsibility to bring the ethical value base of the hospital here to us... and then one also has to see the nurse as a responsible co-worker. .. everyone needs to be involvd in a joint responsibility and tasks... it develops ethical thinking in all of us...

Healthcare organizations thrive from the trust and faith expressed by employees and patients. The Platonic virtue is a genuine truth in the meaning context of healthcare organizations. Virtues are emphasized as the different forms of expression of love and are shown through ethos, serving and the ethical values of healthcare organizations. They are understood to constitute a primary substance that is realized through the good, the truthful and the beautiful in the inner core of caring as an ethical act.

\subsection{Love as providing the ethical movement in the mean- ing context of nursing administrations}

Nurse leaders represent the moral authority of healthcare organizations. This authority is ethical and serving within the context of nursing administrations. It is based on the motive of love and compassion and manifests through serving.

In my work I try to do right or in a way that authority is maintained.

Communion and mutual discussions unite nurse leaders and nurses. To draw attention to and recognize that the fellow human being is unique, contributes to the creation of trust and leads to the nurse leader's being able to feel vitality. Engagement, faith and respect and the unconditional desire to serve originate in trust and the nurse leader's ethos.

ISSN 1927-6990 E-ISSN 1927-7008 
It is primarily the nurse leader who creates the culture and communion in the unit. Simultaneously the ethical and moral actions are brought in.

The caring culture in healthcare organizations offers human beings legitimacy, identity and a sense of communion and belonging. It can be described as a form of communion-bearing collective capital. The motive of love and compassion sets the course for the caring communion based on the ethics of caring, and the ethos of nursing leadership reflects and is rooted in the fundamental driving force and essence of the caring culture. It is possible to draw a parallel between the caring communion and the nurse leaders' deepest and innermost space, where they can openly encounter themselves and their fellow beings in a spirit of a serving communion.

The practice of nursing leadership requires a continuous discussion about what is ethical, the different values connected to ethics... Communication with fellow human beings... As a nurse leader I have to remind myself of the core and be patient... especially if we discuss ethical issues the solution may appear gradually, not the same day. It requires several discussions. Ethical issues are demanding and take time!

Ethical awareness can be the secret to long-term nursing leader posts. It is important for nurse leaders to remind themselves of, to pause and return to their own nursing leadership philosophy and their own ethical, deep values. Ethical awareness is also a clear indicator for nurse leaders' understanding of and compassion for themselves and their own health.

\subsection{The ethical value base in the serving of healthcare organizations and nursing administrations}

The roots of dignity are found in the absolute universal dimension that carry the fundamental values of responsibility, duty, freedom, autonomy and serving. Dignity is the primary value of nursing leadership and a central concept for the ethical nursing administration. Dignity comprises the human being's relation to self and others. Recognition occurs through respect, expression, word, attitude, action and treatment. In dignity complete human value, holiness, human office and calling exist. The highest good, truth and beauty are practical and principled. The practical serving of nursing administrations is visible, conscious, principled, just and reflected in ethos and the ethical core values represented by the healthcare organization.
Factors that affect nursing leadership are how I think, what I am and how dedicated I am to the task. Of course, professional skills have an impact. Probably the most important thing is what kind of relationship I have with the nurses, how I communicate with them and how I show them respect. I firmly believe that the more you respect each other, the more respect you get in return.

The task of nursing administrations is to serve, develop and enable knowledge that contributes to the creation of evidence-based caring. The task is also to aim for the value base and the plans of operations of the healthcare organizations.

To serve is to transform the plan of operations of the healthcare organization so that it works. We receive instructions on how to implement different things and my task is to further manage them. There are ethical rules for how to act. Ethics is something we discuss in different fora.

An ethical and holistic thinking in nursing leadership is central. Nurse leaders have the ability to see the whole and its parts and act based on this. Nurse leaders lead nurses toward common goals set up by the healthcare organization for the meaning context of caring.

\section{Discussion}

The present study asks how nurse leaders through their ethos can pave the way for what is evident, good, truthful and beautiful serving in the context of nursing administrations. The results can increase kept knowledge and deepen the understanding of serving and ethical leadership in nursing administrations.

Serving as a concept has been relatively invisible and has received only scant attention in caring science publications even though it is one of the core concepts of caring science, nursing administrations and caring. Serving refers to the meaning context of caring where nursing leadership is seen as an ethical act. Serving is the essence of love and compassion because these express the human being's dignity and holiness. Serving thus constitutes a foundation for invitation. Compassion offers structure and frames for ethical caring that is based on love and mercy. ${ }^{[10]}$ Serving has a multidimensional nature and can be linked to the experiences of desire, joy and mourning. The opposite and tension of serving can be understood as egoism (see Figure 2). 


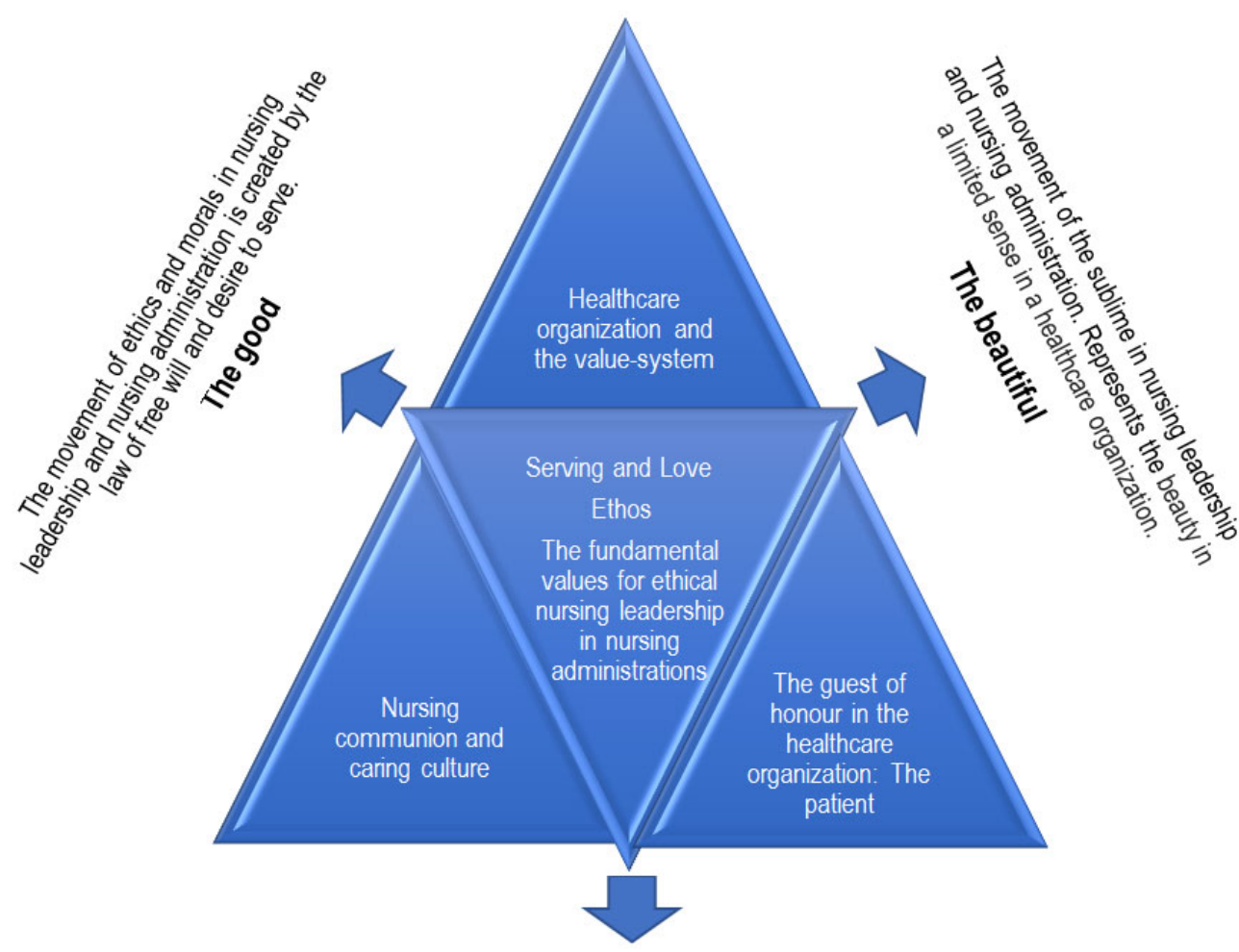

The truthful

The movement of caring science and knowledge in a healthcare organization.

Figure 2. The movements of the good, the truthful and the beautiful created by ethos identifies the origin of serving and ethical nursing leadership in nursing administrations

The ethical discussion about values within healthcare organizations has opened for the primary task-serving and alleviating the patient's suffering. Healthcare organizations are the cornerstones and representatives of society with a significant practical value. They are social units composed of co-active positions. There is a tension in society that asks that the ethical core and moral motive to serve should remain in healthcare organizations. ${ }^{[1,5,8]}$ The ethical value base of healthcare organizations and highlighting the responsibility of nursing administrations to protect the dignity of and alleviating fellow beings' suffering is the common good in the meaning content of caring. ${ }^{[16]}$ A healthcare organization culture based on the serving of nursing administrations and the ethos of nursing leadership promotes a natural and open dialogue between theory and practice. ${ }^{[13]}$ The open dialogue invites belonging and communion. Communion realizes the creation of knowledge. The basic motive of the communion leads to a natural responsibility for one's fellow being where one desires to serve and care for the other.

Serving and ethical nursing leadership are based on the notion that serving is the core and profound driving force in nursing administrations. The common basic note of serving in nursing administrations and ethics is possible to find in the human being in all times and in all contexts. It exists in the depths of the human perception and cannot originate in reason. Serving aims high, has deep roots in caring love and compassion, in the belief in human dignity and respect for the relation and the communion. Its evident good movement is directed towards health and healing. The truthful serving is expressed through the eternal original force and calling of love and compassion, through faith and hope. The last two are reflected through the art of love. Hope brings presence to our time and future possibilities, faith can preserve love. ${ }^{[5]}$

In the context of nursing administrations, it is complicated to allocate love in a logical and exhaustive way. It is simultaneously equivocal and dubious. Love is the key to compassion and understanding the human being and also the understanding of the nurse leaders themselves. ${ }^{[5]}$ In the context of nursing administrations, the concept of love is seldom articulated. The alienation of the concept love has a value difference which means neutrality and emphasizes the nurse leader's potential. This potential may be visible or invisible in acts in nursing administrations and should be based on ethical motives of caring. 
Ethics begins in the nurse leader's innermost being. The point of departure in an ethics that is rooted in ethos offers a stability that invites a deeper understanding. ${ }^{[11,29]}$ Nursing administrations in which the foundation is service, ethics and ethos, are harmonious, effective, learning and promote wellbeing on different levels of healthcare organization. Eriks$\operatorname{son}^{[10]}$ indicates that there are no right answers to ethical problems. There are no absolute truths that can be applied in different difficult ethical situations. A healthcare organization serves patients and every patient and every situation are unique narratives that require ethical standpoints. Nurse leaders' task is to guide nurses toward common goals together with the patient and the patient's next of kin.

Ethos is undoubtedly a fundamental value for human and professional action and must inspire responsible behaviour on the part of nurse leaders who administer health care at all levels, particularly as it pertains to those in direct contact with patients. The positive ethical climate within healthcare organizations need to trigger a virtuous circle in which all those involved feel equally involved, on equal footing, and feel equally vested in serving the patients. It is necessary that nurse leaders and nursing administrations feel that they are all part of the same mission: this sense of belonging to the health care organization should also bring the organizational hierarchies closer, leading to a greater dialogue. The choice to behave in an ethical manner is a daily expression of the will for each and every individual in a health care organization. Since this is a continuous challenge for individuals, it is even more crucial to adhere to ethical values and to build an organization that will further foster these values.
The study shows that a serving and ethical nursing leadership is represented as a compassionate nursing leadership and consists of a rootedness in love and ethos. Within a context of nursing administration, this is applied through caring science cultivation and a caring attitude in nursing leadership, which presupposes ethical competence and kept knowledge. This rootedness leads us to what in nursing leadership is good, truthful and beautiful.

New questions and new evidence-based caring science research emphasize future visions and possibilities for ethical nursing leadership and nursing administrations. These challenges are related to an increased understanding and a discovery of human beings and the changing world, the promotion of health, healing and the alleviation of suffering. For future research it will also be important to support serving and ethical leadership studies through qualitative approach in a variety of settings. Interviews with other health care professionals and listening to leaders who express different or conflicting opinions should always be maintained. In a multicultural society, it is necessary that ethical thinking is not only linked to values of religious origin that belong to a single religion, but rather to create a more inclusive system that would universally apply those who come from different cultural backgrounds.

\section{ACKNOWLEDGEMENTS}

The author thanks PhD N.N. for the professional translation of this manuscript.

\section{CONFLicts OF INTEREST Disclosure}

The author declares no conflicts of interest.

\section{REFERENCES}

[1] Borgenhammar E. Att vårda liv. Organisation, etik, kvalitet. [Caring of life. Organization, ethics, quality]. WSOY: Finland; 1994.

[2] Salminen A. Hallintotiede. Organisaatioiden hallinnolliset perusteet. [The Science of Administration. Administrative Basis of Organizations]. Hallinnon kehittämiskeskus Edita: Helsinki; 2005.

[3] Schein EH. Organisaatiokulttuuri ja johtaminen. [Organizational culture and leadership]. Weilin+Göös: Espoo; 1987.

[4] Senge PM. Den femte disiplinen. Den lärande organisationens konst. [The Fifth Discipline: The Art and Practice of the Learning Organization]. Thomson Fakta AB: Stockholm; 2006.

[5] Honkavuo L. Serva ad ministrare. The ethos of serving in nursing leadership. Åbo Akademi University Press: Åbo; 2014.n

[6] Sennett R. Det fleksible mennesket. Personlige konsekvenser av å arbeide i den nye kapitalismen. [The flexible human. Personal consequences of working in the new capitalism]. Fagbokförlaget AS: Bergen; 2005.

[7] Ahlberg AW, Lundqvist N, Sörbom G. Norstedts latinsk-svenska ordbok. [Norstedt's Latin-Swedish Thesaurus]. AiT: Gjøvik; 2004.
[8] Honkanen H. Muutoksen agentit. Muutoksen ohjaaminen ja johtaminen. [The Agent's of Change. Controlling and Leading Changes] Edita Prima Oy: Helsinki; 2006.

[9] Berg Eriksen T, Tranøy KE. Filosofi og vitenskap. Fra antikken til høymiddelalderen. [Philosophy and Science. From Ancient Times to The Middle Ages]. Universitetsforlaget: Oslo; 1991.

[10] Eriksson K. Mot en caritativ vårdetik. [Towards caritative nursing ethics]. Åbo Akademi: Vasa; 1995.

[11] Eriksson K. Ethos. In: Eriksson K, Lindström UÅ. (eds.). Gryning II Klinisk vårdvetenskap. [The Dawn II. Clinical Caring Science]. Åbo Akademi: Vasa; 2003.

[12] von Wright GH. Logik, filosofi och språk. Strömningar och gestalter i modern filosofi. [Logics, philosophy and language. Streams and figures in modern philosophy]. Bokförlaget Nya Doxa: Nora; 1993.

[13] Eriksson K, Nordman T. (eds). Den Trojanska hästen II. Utvecklandet av evidensbaserade vårdande kulturer. [The Trojan Horse II. Developing evidence-based caring cultures]. Åbo Akademi: Vasa; 2004.

Published by Sciedu Press 
[14] Eriksson K, Lindström UÅ, Kasén A, et al. Ethos anger siktet för vårdvetenskap vid Åbo Akademi. [Ethos indicates the sight in caring science at Åbo Akademi]. Hoitotiede. 2006; 18(6): 296-298.

[15] Eriksson K. Etik och evidens. In: Martinsen K, Eriksson K. Å se og å innse. Om ulike former for evidens. [To see and to realize. About various forms of evidence]. Akribe AIT: Otta AS; 2009.

[16] Edlund M. Människans värdighet. Ett grundbegrepp inom vårdvetenskapen. [Human Dignity. A Basic Concept in Caring Science]. Åbo University Press: Åbo; 2002.

[17] Lévinas E. Etik och oändlighet. Samtal med Philippe Nemo. [Ethics and Infinity. A Conversation with Philippe Nemo]. Symposion Bokförlag: Stockholm/Lund; 1990.

[18] Wattles J. The Golden Rule. Oxford University Press Inc.: New York, 1996.

[19] Detert JR, Treviño LK, Burris ER, et al. Managerial modes of influence and counterproductivity in organizations: a longitudinal business-unit-level investigation. Journal of Applied Psychology. 2007; 92(4): 993-1005. PMid:17638460. https://doi.org/10 $.1037 / 0021-9010.92 .4 .993$

[20] Hannah ST, Schaubroeck JM, Peng AC, et al. Joint influences of individual and work unit abusive supervision on ethical intentions and behaviours: a moderated mediation model. Journal of Applied Psychology. 2013; 98(4): 579-92. PMid:23647209. https: //doi.org/10.1037/a0032809

[21] Rabindra NK. Ethical values of transactional and transformational leaders. Canadian Journal of Administrative Sciences. 2001; 18(4): 257-265.

[22] Kalshoven K, Den Hartog DN. Ethical Leader Behavior and Leader Effectiveness: The Role of Prototypicality and Trust. International Journal of Leadership Studies. 2009; 5(2): 102-120.

[23] Cara CM, Nyberg JJ, Brousseau S. Fostering the Coexistence of Caring Philosophy and Economics in Today's Health Care System. Nursing Administration Quarterly. 2011; 35(1): 6-14. PMid:21157259. https://doi.org/10.1097/NAQ. 0b013e3182048c10

[24] Bjarnason D, Lasala CA. Moral Leadership in Nursing. Journal of Radiology Nursing. 2011;30: 18-24. https://doi.org/10.101 $6 / j \cdot$ jradnu. 2011.01.002

[25] Makaroff KS, Storch J, Pauly B, et al. Searching for ethical leadership in nursing. Nursing Ethics. 2014; 21(6): 642-658. PMid:24418739. https ://doi.org/10.1177/0969733013513213

[26] Van Dierendonck D, Nujiten I. Develpoment and Validation of a Multidimensional Measure. Journal of Business and Psychology. 2011; 26(3): 249-267. PMid:21949466. https://doi .org/10.1007/s1 0869-010-9194-1
[27] Patterson KA. Servant leadership: A theoretical model. Regent University. Dissertations Abstract International 2003; 64(2).

[28] Rushton CH, Schoonover-Shoffner K, Kennedy MS. Executive Summary: Transforming Moral Distress into Moral Resilience in Nursing. American Journal of Nursing. 2017; 117(2): 52-55. PMid:28125491. https://doi.org/10.1097/01.NAJ .0000512298.18641.31

[29] Mannix J, Wilkes L, Daly J. 'Good ethics and moral standing': a qualitative study of aesthetic leadership in clinical nursing practice. Journal of Clinical Nursing. 2015; 24(11-12): 1603-1610.

[30] De Hoogh AHB, Den Hartog DN. Ethical and despotic leadership, relationships with leader's social responsibility, top management team effectiveness and subordinates' optimism: A multi-method study. The Leadership Quarterly. 2008; 19: 297-311. https://doi .org/ $10.1016 / \mathrm{j}$. leaqua. 2008.03.002

[31] Greenleaf R. The Power of Servant Leadership. Berret-Koehler Publishers, Inc.: San Francisco; 1998.

[32] Barkhordari-Sharifabad M, Ashktorab T, Atashzadeh-Shoorideh F. Ethical leadership outcomes in nursing. Nursing ethics. Online Referencing: January 18 2017. https://doi.org/10.1177/096973 3016687157

[33] Jeon SH, Park M, Choi K, et al. An Ethical Leadership Program for Nursing Unit Managers. Nurse Education Today. 2018; 62: 30-35. PMid:29277076. https://doi.org/10.1016/j.nedt.2017.12 .017

[34] Linette D, Sherman RO. Transforming a Practice Environment Through Caring-Based Nursing Leadership. Nurse Leader. 2014; 12(1): 35-38. https://doi.org/10.1016/j.mnl.2013.09.01 4

[35] Neill MV, Saunders NS. Servant leadership: enhancing quality of care and staff satisfaction. Journal of Nursing Administration. 2008; 39(9): 395-400.

[36] Gadamer HG. Truth and Method. Bloomsbury Academic: London; 2013.

[37] Kvale S, Brinkmann S. Den kvalitativa forskningsintervjun. [The Qualitative Interview]. Studentlitteratur AB: Lund; 2014.

[38] World Medical Association Declaration of Helsinki (WMA). Ethical Principles for Medical Research Involving Human Subjects; 2012.

[39] Northern Nurses' Federation (NNF). 2011.

[40] The International Council of Nurses, 2006. The ICN Code of Ethics for Nurses.

[41] Norwegian social science data services NSD. 2007. Available from: http//www.nsd.uib.no 